\title{
Assessment on awareness towards preventive measures of COVID-19 in Sheka, Ethiopia: Community based cross-sectional Study
}

Assaye Belay Gelaw ( $\sim$ abstat23@gmail.com )

Mizan-Tepi University https://orcid.org/0000-0001-7315-9141

Solomon Abebaw Andargie

Mizan-Tepi University

Research article

Keywords: Awareness, Prevention, COVID-19, Pandemic, Knowledge

Posted Date: January 6th, 2021

DOI: https://doi.org/10.21203/rs.3.rs-30820/v3

License: (c) (i) This work is licensed under a Creative Commons Attribution 4.0 International License.

Read Full License 


\section{Abstract}

Background: The coronavirus disease 2019 (COVID-19) is caused by severe acute respiratory syndrome coronavirus 2 (SARS-CoV-2), and it is the most important of public health problem worldwide. A critical element in tackling the COVID-19 crisis is personal behavioral change; however, there is a paucity of evidence about peoples' awareness towards COVID-19 pandemic. Hence, this study was aimed to assess the people's awareness status towards COVID-19 in Sheka, Southwestern Ethiopia.

Methods: Community-based cross-sectional study was conducted between $10^{\text {th }}$ to $21^{\text {th }}$ April 2020 . Four hundred-nineteen individuals participated during the study. Both univariable and multivariable logistic regression analyses were used to identify significant factors of awareness status, and variables with $p$ value $<0.05$ indicated it significantly influences the awareness status of the individuals towards COVID-19.

Results: According to the study's results, nearly half (49.4\%) of the participants had awareness about COVID-19 pandemic. Factors such as sex, education level, religion, symptom, and knowing prevention methods were significantly associated with awareness of individuals towards COVID-19 pandemic. Respondents who did know all prevention methods (AOR: $8.1,95 \% \mathrm{Cl}: 1.3,51.9$ ) are more likely to aware of COVID-19 than their counterparts.

Conclusion: The study showed that there is a low awareness status among people towards COVID19. Hence, programs to improve awareness towards COVID-19 pandemic is is essential to prevent and control the pandemic.

\section{Background}

Coronavirus is among the diverse families of viruses and a source of illness of the disease ranging from the common cold to more several diseases such as middle respiratory syndrome [1] .COVID-19 case was first reported on 31 month of December 2019 in Wuhan city of China. Since then, it has been rapidly spreading as infectious disease, which has now developed to the global pandemic. The pandemic is affecting all major world economies; predicting to cause huge global economic crisis in 2020. Currently, the virus is spreading to the entire world and can infect people of all age groups. Older people and those with pre-existing medical history problems are more vulnerable to becoming severely ill with the virus [25]. COVID-19 is transmitted through droplets and fomites during close unprotected contact between an infected and healthy person. The airborne spread has not been reported for COVID-19, and there is no big driver of transmission based on available evidence [6].

Novel coronavirus case was first happened in Ethiopia on the $13^{\text {th }}$,March 2020 and preventive measures against COVID-19 is continuing in all parts of the country[7].

Declines in tourism and business travel, spillovers of weak demand to other sectors and economies through trade and production linkages; supply-side disruptions to production and trade (which are distinct from demand-side shocks spilling over through trade and production linkages); and effects on health 
such as increased disease and mortality as well as shifts in health care spending are the major impacts of COVID-19 pandemic [8-10]. The COVID-19 is affecting educational systems worldwide, and it is leading to the widespread closures of schools and universities. The virus affected over 1.5 billion students worldwide, accounting for $87 \%$ of enrolled learners[11].

To date, there is no specific vaccine or treatment recommended to prevent COVID-19. Though messages related to COVID-19 transferred from health professionals and the concerned bodies frequently, still the utilization of preventive measures is low in our observation. A critical element in tackling the COVID-19 crisis is public behavior change. Behavior change requires public understanding, acceptance, and implementation of the recommended prevention methods. There is a paucity of evidence showing the status of individual awareness towards COVID-19 in Ethiopia. Thus, this study was aimed at assessing the awareness status of people towards COVID-19 in Sheka, Southwestern Ethiopia.

\section{Methods}

\section{Study area and design}

The current study was conducted in Sheka; Southwestern Ethiopia, and Masha town. Masha is located $951 \mathrm{Km}$ to North West of Awassa, the capital of SNNPR and $676 \mathrm{~km}$ to Southwest of Addis Ababa. Sheka is bordered on the south by Benchi-Sheko, on the west by the Gambela Region, on the north by the Oromiya Region, and on the east by Kaffa Zone. Administratively, the Sheka Zone is structured into three provinces and two city administrations. A community-based cross-sectional study was conducted between $10^{\text {th }}$ to $21^{\text {th }}$ of April 2020. The study populations were all those who are living in Sheka Zone, Southwestern Ethiopia.

\section{Sampling Procedure}

Sample size was calculated using a single population proportion formula, and simple random sampling technique. Confidence level, margin of error, and expected maximum proportion were considered for calculating the sample size [12].The required sample size was computed asis at $95 \%$ confidence level for normal distribution, which is 1.96 ,is a margin of error (5\%), and $10 \%$ none response rate was considered. Thus, considering (a maximum proportion for the awareness of individuals about COVID-19 pandemic because of no previous study was done), the sample size for this study becomes $384.5+38.5 \sim 424$.

\section{Data collection tools and procedure}

The data were collected using structured interview with administered questionnaire that was prepared based on the study objectives. The questionnaire was translated into the local language that is Amharic. Six health extension workers were engaging for twelve days (April 10-21 April 2020) for data collection. One-day training was given for data collectors by the investigators to control the quality of data.

\section{The study variables}


The outcome variable was the awareness status of participants dichotomized as awared and not awared (measured from understanding towards COVID-19 pandemic). Somebody is awared when she or he did know about COVID-19 prevention methods and control mechanism and not aware when the participants have poor understanding in the direction of COVID-19 prevention methods and control mechanism.

The socio-demographic factors such as age, sex, level of education, religion, source of income, prevention method used, knowing symptoms, use of quarantine, treatment, source of information, level of implementing of government and health professionals' declaration perceived by individuals, and preexisting health condition of participants were measured from structural administered questionnaires.

\section{Data analysis}

Data were analyzed using SPSS software package (version 20). Frequency distribution, percentage, and plots were used to provide sound results[13].The chi-square test was applied to examine the association between factors and the dependent variable. The logistic regression model was used to express the dependent variable or the response variable qualitatively expressed[14].

Binary logistic regression is the form of regression, which is used when the dependent variable is dichotomous, and the independent variables are any type. A binary variable has only two possible values, such as presence or absence of a particular event, in our study to identify whether the participants had awareness towards COVID-19 pandemic not. 
Model $: \ln \left(P_{i} / 1-P_{i}\right)=\beta_{0}+\beta_{1} X_{1 i}+\beta_{2} X_{2 i}+\ldots \ldots \ldots \beta_{k} X_{k i}$.

$P_{i} / 1-P_{i}=\exp \left(\beta_{0}+\beta_{1} X_{1 i}+\beta_{2} X_{2 i}+\ldots \ldots \ldots \beta_{k} X_{k i}\right)$. Where $P_{i}$ is the probability of success, $1-P_{i}$ is theprobability of failure, $\beta_{0}$ is constant term, $\beta$ regression coefficients and $X_{i}$ is independent variables.

The odds are simply the ratio of the probabilities for the two possible outcomes[15].If $P_{i}$ is the probability that an event will occur, and then $1-P_{i}$ is the probability that an event will not occur. odds $=\frac{p_{i}}{1-p_{i}}$. Let in $2 \times 2$ tables, within row 1 the odds of success are odds $1=p_{1} / 1-p_{1}$ and within row 2 the odds of success equal odds $s_{2}=p_{2} / 1-p_{2}$. The ratio of the odds from the two rows (odd ratio) is given byodds Ratio $=\theta=\frac{\text { odd } s_{1}}{\text { odd } s_{2}}=p_{1} / 1-p_{1} / p_{2} / 1-p_{2}$.

\section{Parameters Estimation}

The maximum likelihood and Wald test were used for parameter estimation methods in fitting logistic regression model.

The maximum likelihood estimates of the parameters could be obtained by maximizing the loglikelihood function from (ii) is given by $p_{i}=\frac{e^{\left(\beta_{0}+\beta_{1} X_{1 i}+\beta_{2} X_{2 i}+\ldots \ldots \ldots \beta_{k} X_{k i}\right)}}{1+e^{\left(\beta_{0}+\beta_{1} X_{1 i}+\beta_{2} X_{2 i}+\ldots \ldots \ldots \beta_{k} X_{k i}\right)}}$ [14]. Since observe values of $Y$ say, $Y_{i}^{\prime}$ s $(i=1,2 \ldots n)$ are independently distributed as Bernoulli, the maximum likelihood function of $\mathrm{Y}$ is given by:

$$
L(\beta / y)=\prod_{i=1}^{n} p\left(y_{i} / x_{i}{ }^{i}\right)=\prod_{i=1}^{n}\left[\frac{e^{x_{i}{ }^{\prime} \beta_{i}}}{1+e^{x_{i}{ }^{i} \beta_{i}}}\right]^{y_{i}}=\left[\frac{1}{1+e^{x_{i}{ }^{\prime} \beta_{i}}}\right]^{\left(1-y_{i}\right)}
$$

Wald $\chi^{2}$ statistics is used to test the significance of individual coefficients in the model and are calculated as follows: Wald $=\left[\frac{\beta}{\operatorname{se}(\beta)}\right]^{2} \sim \chi^{2}$ distribution with one degree of freedom.

\section{Assessments of the fitted model}

The Wald test is the most computing parameter estimation method for logistic regression method. After the model is fitted, the next important step is checking the model adequacy. Therefore, the HosmerLemeshow test was used [16].

\section{Results}


The socio-demographic factors of the study participants were illustrated in Table 1. Four hundrednineteen respondents participated in the survey and among the respondents, 207 (49.4\%) had awareness, and 212 (50.6\%) did not have an awareness towards COVID-19 pandemic, which was an almost equal proportion of awareness. Of the total respondents, males accounting, 97(46.9\%), and females accounting, 110 (53.1\%) had awareness towards COVID-19 pandemic.

Table 1.Socio-demographic characteristics of the study participants $(n=419)$ 


\begin{tabular}{|c|c|c|c|c|c|}
\hline \multirow[b]{2}{*}{ Variables } & \multicolumn{2}{|c|}{ Awareness status (\%) } & \multicolumn{3}{|c|}{ Chi-square } \\
\hline & Categories & Yes & No & df & $\begin{array}{l}\text { P- } \\
\text { value }\end{array}$ \\
\hline \multirow[t]{2}{*}{ Gender } & Male & $\begin{array}{l}97 \\
(46.9)\end{array}$ & $68(32.1)$ & 1 & 0.002 \\
\hline & Female & $\begin{array}{l}110 \\
(53.1)\end{array}$ & $\begin{array}{l}144 \\
(67.9)\end{array}$ & & \\
\hline \multirow[t]{6}{*}{ Age } & Less than 20 & $15(7.2)$ & $5(2.4)$ & 5 & 0.009 \\
\hline & $20-29$ & $\begin{array}{l}88 \\
(42.5)\end{array}$ & $65(30.7)$ & & \\
\hline & $30-39$ & $\begin{array}{l}59 \\
(28.5)\end{array}$ & $89(42.0)$ & & \\
\hline & $40-49$ & $\begin{array}{l}31 \\
(15.0)\end{array}$ & $34(16.0)$ & & \\
\hline & $50-59$ & $8(3.9)$ & $11(5.2)$ & & \\
\hline & $>=60$ & $6(2.9)$ & $8(3.8)$ & & \\
\hline Education & Illiterate & $33(15.9)$ & $29(13.7)$ & 2 & 0.539 \\
\hline \multirow[t]{2}{*}{ Level } & Primary level & $\begin{array}{l}75 \\
(36.2)\end{array}$ & $\begin{array}{l}119 \\
(56.1)\end{array}$ & & \\
\hline & Secondary \& above & $\begin{array}{l}99 \\
(47.8)\end{array}$ & $64(30.2)$ & & \\
\hline \multirow[t]{5}{*}{ Religion } & Orthodox & $\begin{array}{l}107 \\
(51.7)\end{array}$ & $106(50)$ & 4 & 0.000 \\
\hline & Muslim & $\begin{array}{l}47 \\
(22.7)\end{array}$ & $56(26.4)$ & & \\
\hline & Catholic & $\begin{array}{l}22 \\
(10.6)\end{array}$ & $4(1.9)$ & & \\
\hline & Protestant & $\begin{array}{l}23 \\
(11.1)\end{array}$ & $21(9.9)$ & & \\
\hline & Others & $8(3.9)$ & $25(11.8)$ & & \\
\hline \multirow{3}{*}{$\begin{array}{l}\text { Source of } \\
\text { income }\end{array}$} & Daily workers & $\begin{array}{l}59 \\
(28.5)\end{array}$ & $68(32.1)$ & 2 & 0.089 \\
\hline & Trade & $\begin{array}{l}77 \\
(37.2)\end{array}$ & $92(43.4)$ & & \\
\hline & Salary & $\begin{array}{l}71 \\
(34.3)\end{array}$ & $52(24.5)$ & & \\
\hline Prevention & Partially used & $58(28)$ & $95(44.8)$ & 2 & 0.001 \\
\hline
\end{tabular}


Methods

used by individuals

Treatment

assumed by

Participants

Source of

information

Use of

Quarantine

Knowing symptom of COVID-19

Pre-existing

health level

of participants

Level of
Fully used

No idea

Treatment

No any treatment

No idea

Television

Radio

Health professional

All

No idea before

Know

No idea

High pulmonary pain and difficult to breath

Fever \& Dray Cough

All

No idea

Normal

Diabetic Mellitus

Addiction

Hypertension

HIV

Pregnancy

Seizure

Renal disease

Fair
$144 \quad 115$

(69.6) (54.2)

$5(2.4) \quad 2(0.9)$

$17(8.2) \quad 31(7.4) \quad 2 \quad 0.418$

$137 \quad 269$

(66.2) (64.2)

$53 \quad 119$

(25.6) (28.4)

$\begin{array}{llll}76 & 74(39.9) \quad 4 & 0.006\end{array}$

(36.7)

$10(4.8) \quad 16(7.5)$

$64 \quad 37(17.5)$

(30.9)

55

77 (36.3)

(26.7)

$2(0.9) \quad 8(3.7)$

$203 \quad 210(99.1) \quad 1 \quad 0.394$ (98.1)

$4(1.9) \quad 2(0.9)$

$2(1) \quad 10(4.7) \quad 3 \quad 0.002$

27 (13) 40 (18.9)

$131 \quad 99(46.7)$

(63.3)

$47 \quad 63(29.7)$

(22.7)

167

(80.7)

157

(74.1)

8 (3.9) $\quad 12(5.7)$

$11(5.3) \quad 2(0.9)$

7 (3.4) $\quad 15(7.1)$

$4(1.9) \quad 6(2.8)$

$6(2.9) \quad 14(6.6)$

$1(0.5) \quad 4(1.9)$

3 (1.4) $2(0.9)$

$98 \quad 123$ 
implementation

Medium

perceived
High

Very high

No idea
68

(32.9)

22

(10.6)

13 (6.3) $3(1.4)$

6 (2.9) 4 (1.9)
74 (34.9)

8 (3.8)

The educational level of respondents increased proportion of awareness of the COVID-19 pandemic. The percentage of understanding is $(15.9 \%)$ for non-educated participants, $(36.2 \%)$ for primary educated participants and (47.8\%) for respondents whose education level is secondary and above had an awareness of COVID-19.

Concerning the source of information,76 (36.7\%), 10 (4.8\%), 64(30.9\%), 55(26.7\%) and 2(0.9\%) of respondents obtained information about COVID-19 from Television, Radio, Health professionals, and no source information respectively had an awareness of COVID-19 pandemic.

Table 1 also illustrated prevention methods recommended by the world health organization (WHO) that were used by the respondents. Thus,58 (28\%), $144(69.6 \%)$ and $5(2.4 \%)$ of respondents used prevention methods partially, fully used or apply all WHO recommended prevention methods and no idea for prevention or they did not apply WHO recommended prevention methods respectively had an awareness of COVID-19 diseases.

$210(99.1 \%)$ of participants who were informed about the use of quarantine were aware of the preventive measures of COVID-19 while, $2(0.9 \%)$ of those who had no idea about the quarantine were not aware.

Table 1 also shows the pre-existing health level of respondents; the pre-existing health level of respondents were 324 (77.3\%), 20 (4.8\%), 13(3.1\%), 22(5.3\%), 10(2.4\%), 20 (4.8\%) and $5(1.2 \%)$ respectively are normal, diabetic mellitus, addiction, hypertension, HIV+, pregnancy, seizure, and renal disease. The participants' awareness status differed significantly across/among all socio-demographic except for, the source of income, treatment, use of quarantine or isolation, and educational level.

Figure 1 show that 52.74 percent of respondents fairly implemented, 33.09 percent applied in the medium, 7.16 percent applied highly implemented, 2.39 percent implemented too high, and 0.48 percent not implemented for government declaration towards COVID-19 pandemic.

Figure 2 showed that the probability of the individual's awareness towards COVID-19 is decreasing, whereas the chance those individuals will not be aware of COVID-19 increases. It implies an awareness creation strategy to maximize the individual's awareness of COVID-19 pandemic. 
The $\chi 2$ statistic with 8 degrees of freedom is 14.911 , and the $p$-value is 0.06 . Thus, the model well fitted the data (Table 2).

\section{Table 2: Hosmer and Lemeshow Test of good ness of fit}

\begin{tabular}{lll}
\hline Chi-square & df & Sig. \\
14.911 & 8 & 0.061
\end{tabular}

A classification table used to distinguish accurately predicted value of awareness of respondents towards COVID-19 (Table 3). The table is indicating the validity of predicted probabilities (Table 3 ). The first two rows in Table 3 stands for the two possible outcomes, and the two columns under the heading predicted are for high and low probabilities.

Table 3. The Observed and the Predicted Frequencies for Awareness of Respondents towards COVID-19 by Logistic Regression with the Cutoff of 0.50

\begin{tabular}{lrrrr}
\hline Observed & \multicolumn{4}{c}{ Predicted } \\
\cline { 3 - 5 } & \multicolumn{4}{c}{ Awareness Percentage Correct } \\
\hline Awareness & yes & 148 & 59 & 71.5 \\
& No & 50 & 162 & 76.4 \\
Overall Percentage & & & 74.0
\end{tabular}

Note. Sensitivity $=148 /(148+59) \%=71.5 \%$. Specificity $=162 /(50+162) \%=76.4 \%$.

False positive $=50 /(148+50) \%=25.5 \%$. False negative $=59 / 59+162) \%=26.7 \%$.

The observation also held in the sensitivity $(71.5 \%)$ as compared to that of specificity $(76.4 \%)$. Sensitivity measured the correct proportion of classified events (the awareness of individuals towards COVID-19). Specificity measures the true proportion of classified non-events (those not suggested for awareness of individuals towards COVID-19). Both false positive and false negative rates are a little more than $25 \%$. The false positive and false-negative rate respectively measure the proportion of observing misclassified as events and miss classified as non-events. Thus, the overall correction prediction was $74 \%$ on the progress over the chance level to aware of the COVID-19 pandemic.

The results from multivariable analysis revealed that sex, religion, education level, understanding prevention methods were factors associated with awareness status of COVID-19(Table 4). 
Table 4. Parameter estimates of binary logistic regression using forward stepwise variable selection Method.

\begin{tabular}{|c|c|c|c|c|c|c|c|c|c|}
\hline \multirow[t]{2}{*}{ Variables } & \multirow[t]{2}{*}{ Categories } & \multirow[t]{2}{*}{$\beta$} & \multirow[t]{2}{*}{ S.er. } & \multirow[t]{2}{*}{ Wald } & \multirow{2}{*}{\multicolumn{2}{|c|}{$\begin{array}{l}\text { df P- } \\
\text { value }\end{array}$}} & \multirow[t]{2}{*}{ AOR } & \multicolumn{2}{|c|}{$\begin{array}{c}\text { 95\% C.I. for } \\
\text { EXP(B) }\end{array}$} \\
\hline & & & & & & & & Lower & Upper \\
\hline \multirow[t]{2}{*}{ Sex } & Male (ref) & & & & & & & & \\
\hline & Female & -0.743 & 0.247 & 9.061 & 1 & 0.003 & 0.476 & 0.293 & 0.772 \\
\hline \multirow[t]{3}{*}{ education } & Illiterate(ref) & & & & & & & & \\
\hline & Elementary & -0.349 & 0.361 & .933 & 1 & 0.334 & 0.706 & 0.348 & 1.431 \\
\hline & Secondary + & 0.779 & 0.254 & 9.374 & 1 & 0.002 & 2.178 & 1.323 & 3.586 \\
\hline \multirow[t]{5}{*}{ Religion } & Orthodox (ref) & & & 15.395 & 4 & 0.004 & & & \\
\hline & Muslim & -1.238 & 0.493 & 6.300 & 1 & 0.012 & 0.290 & 0.110 & 0.762 \\
\hline & Catholic & -1.048 & 0.522 & 4.026 & 1 & 0.045 & 0.351 & 0.126 & 0.976 \\
\hline & Protestant & -2.879 & 0.749 & 14.771 & 1 & 0.000 & 0.056 & 0.013 & 0.244 \\
\hline & Others & -1.327 & 0.576 & 5.301 & 1 & 0.021 & 0.265 & 0.086 & 0.821 \\
\hline \multirow[t]{7}{*}{ Symptoms } & $\begin{array}{l}\text { Pulmonary and difficult to } \\
\text { breath (ref) }\end{array}$ & & & & & & & & \\
\hline & fev,dry cough & 1.718 & 0.979 & 3.076 & 1 & 0.079 & 5.572 & 0.817 & 37.991 \\
\hline & All & 0.265 & 0.401 & .436 & 1 & 0.509 & 1.303 & 0.594 & 2.857 \\
\hline & Don't know & -0.541 & 0.285 & 3.593 & 1 & 0.058 & 0.582 & 0.333 & 1.019 \\
\hline & Partially(ref) & & & & & & & & \\
\hline & Fully used & 2.095 & 0.946 & 4.908 & 1 & 0.027 & 8.127 & 1.273 & 51.871 \\
\hline & None of used & 1.384 & 0.950 & 2.122 & 1 & 0.145 & 3.990 & .620 & 25.673 \\
\hline
\end{tabular}

$*=\mathrm{P}<0.05 *$

The odds ratio (OR) of education (secondary and above) equal to $\exp (0.779)=2.178(95 \% \mathrm{Cl}: 1.323$, 3.586) (adjusted other variables). The respondents whose education level is secondary and above education level are 2.178 times more likely to aware of COVID-19 than respondents whose education level is illiterate(Table 4). The odds ratio (OR) of religion (muslim, catholic, protestant and others) are respectively equal to $\exp (-1.238), \exp (-1.048)$, $\exp (-2.879)$, and $\exp (-1.327)=0.290,0.351$ and 0.056 , 0.265 [95\% Cl: $(0.110,0.762) ;(0.126,0.976) ;(0.013,0.244) ;(0.086,0.821]$ (adjusted others variables). The respondents whose religion,muslim,catholic, protestant, and others respectively are $0.290,0.351$, 0.056 and 0.265 times less likely to aware of COVID-19 pandemic than those respondents whose religion is orthodox (Table 4).

The odd ratio of prevention method (fully used) equal to $\exp (2.095)=8.127(95 \% \mathrm{Cl}: 1.273,51.871)$ (other variables are adjusted) is 8.127 times more likely to aware about COVID-19 pandemic than those respondents partially used (at most three prevention method have used). 


\section{Discussion}

Now days, the COVID-19 pandemic is accelerating worldwide. The Ethiopian government is taking many measurements to tackle the impact of COVID-19 on any business sector and the wellbeing of individuals. It is, therefore, mandatory to explore the effects of COVID-19 in Ethiopia and to set out immediate priorities and longer-term strategies for appropriate interventions. Culturally, in Ethiopia, it is hard to apply all COVID-19 prevention strategies since individuals are highly sociable, culturally indispensable among each other, and the marketing system is traditional.

The COVID-19 is a current language spoken by almost all media all over the world. However, society is still not aware of the risk of COVID-19 pandemic. The study showed that $50.6 \%$ of participants did not have awareness about the COVID-19 pandemic. The overall correction prediction value was $74 \%$. It is an improvement over the chance to be aware of the COVID-19 pandemic, and $26 \%$ chances did not get being aware of COVID-19. The current study is consistent with the study done in the awareness of the individual towards COVID-19 disease[17].

Hence, much effort is needed to be done towards awareness for the individual about COVID-19 by assessing socio-demographic factors and the individual's perception towards COVD-19 pandemic management. Quarantine is one mechanism to control the coronavirus pandemic. The study showed that about ninety-eight percent of the societies had awareness about quarantine. The current study is consistent with the study done in Middle East Respiratory Syndrome Coronavirus epidemic impact on healthcare workers' risk perceptions, work and personal lives[18] and also consistent with the study conducted in Vietnam where $97.9 \%$ of the participants agree to quarantine[19].

According to the world health organization (WHO) advice, the individual expected to be high risk by COVID-19 pandemic if their current health level is pregnancy, seizure, hypertension, diabetic Miletus, addiction, HIV, chronic pulmonary and chronic renal disease. The study showed that people with diabetic Miletus, hypertension, HIV, and renal disease patients considered to be at high risk of suspected to COVID19 infection.

Thus, special attention should be given to the high susceptive society in the town administration by creating awareness about the COVID-19 pandemic (table 1). According to this study, $2.39 \%$ of participants never implemented the government, and health professions advice how to prevent coronavirus pandemic prevention strategies (figure 1). Henceforth, the results need much intervention tall prevention strategies towards COVID-19 to the individual.

Currently, there is no vaccine or treatment to coronavirus pandemic. However, still, there is a myth that there is vaccine to prevent the disease. In the study, $8.2 \%$ of individuals assumed that there is a vaccine, and these results showed that it is risky to manage the pandemic. The level of implementation of government and health professional declaration regarding COVID-19 pandemic overall prevention strategies are questionable since some individuals were not still implementing the government declaration. 
The awareness of some individuals depends on religious aspects. Some religions may preach that the disease becomes from God and so that it is so hard to stop by government declaration and health professionals. The model may tell us some religions are less aware (religion concern) than other religions even if we cannot recommend which religion is better. As it is known, the Ethiopian religious association agreed to announce declaration for one month to pray to tackle the hidden challenge of the pandemic, which is an unseen enemy causing multitude of socio-economic crisis all over regardless of all aspects in the world.

The study found that mass media and public health care workers were the most important sources of information in Sheka Zone, Tepi Town administration for individual's awareness towards COVID-19 pandemic. This finding is similar to Myanmar adults study because it used the familiar sources which are social media and mass media[20]. Also the study conducted in Hong Kong in which their common sources were social platform and mass media but different with health care workers study in which their primary sources were not only social media but also official government websites[21], [22] and in Pakistan healthcare professionals study reveal the same result with the current study [23].

The multivariable binary logistic regression was used to identify the factors influencing society's awareness of COVID-19. The results showed that sex, educational level, and preventive strategies are significant factors in the understanding of individuals. These findings were similar to the study conducted in Myanmar adults on awareness, perceived risk, and protective behaviors to COVID-19 and in Saudi Arabia[20], [24].

\section{Limitation of study}

Though the investigators did their best to assess the factors and status of peoples' awareness towards preventive measures of COVID-19, it is not free from limitations. The survey was conducted as early as the pandemic on set in Ethiopia. Consequently, more literatures were not incorporated for supporting the designation of the methodology.

\section{Generalizability of the results}

The study results are generalized on the whole population because of the study used probability sampling technique, and appropriate procedures. Thus, more than ninety-eight percent of participants actively participated during the survey.

\section{Conclusion}

The finding highlights the awareness status in Sheka, South Nation Nationalities' Peoples of Region, Tepi town administration, Southwestern part of Ethiopia, and individuals presently practicing concerning COVID-19 pandemic. The study assessed individuals' awareness and experience in the direction of COVID-19 pandemic. According to our finding, the main factors for being aware are gender being female, education level being secondary and above level, religion, knowing symptoms of COVID-19 and 
prevention strategies. The study found that below half of the respondents $(49.4 \%)$ agreed on the essential role of individuals in the prevention of COVID-19 pandemic and they decided to inform suspected instances to any involved health care workers and follow the directions of the ministry of health authorities and the establishment policies to forestall the pandemic. Also, the finding confirmed that more than half $(50.6 \%)$ of the individuals had no awareness and poor protecting experience to prevent COVID19 pandemic. The study found 54.18 percent of the individuals fairly implemented and 0.48 percent of the individuals did not put into effect the government declaration strategies to stop COVID-19 pandemic. The study was also capable of highlighting gaps in the precise element of perception and preventive experience that should center in future attention and instructional campaigns.

The study recommends extra teaching involvement and movements are required for all individuals to help them with the awareness of the capacity of transmission, the symptoms and prevention strategies. The study also recommends the ministry of health authorities, public health care professionals, other countrywide and worldwide health organizations, mass media, social media and all concerned bodies to make promoting and put in force of all protecting and preventive measures of COVID-19 pandemic in the direction of the individuals. Further studies should be warranted in country level and explore other factors that are not addressed in this study.

\section{Abbreviations}

CDC: Centers for Disease Control and Prevention

COVID-19: Coronavirus Disease 2019

AOR: Adjusted Odd Ratio

WHO: World Health Organization

SNPPR: South Nation Nationalities and Peoples of Region

\section{Declarations}

\section{Ethics approval and consent to participate}

Written permission was obtained from Mizan-TepiUniversity, with reference number MTU/19/86//09/2020 to Tepi Town Public Health Office and then they approved it.

The Approval Committees Were:

i. Yideg Mamo, Chief Executive of Mizan-Tepi University,e-mail:mamoyideg@gmail.com

ii. Bizuwork Derebew: College of Natural and Computational Science, Dean,e-mail:bususi@gmail.com

iii. Abatneh Baye, Head of Public Health, City Administration, and Phone №:+251-917187502

iv. Yetmwork Aragie, Public Health Officer, City Administration, and Phone №:+251-906413734 
The participants were told them about the study objectives and the provided information kept confidentially. They were also told them that they have the right to say no the interview even in the at the time of survey if they are inconvenient

\section{Consent for Publish}

Not applicable

\section{Availability of data and materials}

The data will be given upon on request behalf of corresponding author.

\section{Competing interests}

No potential conflicts of interest declared.

\section{Funding}

The fund was sponsored by Mizan-Tepi University for data collection, and design of the study. However, there is no role for data analysis, interpretation and in writing the manuscript.

\section{Authors 'contributions}

Both authors were responsible for the conception, data analysis, interpretation of the results, writing manuscript. Finally all authors had read and approved the manuscript.

\section{Acknowledgments}

All who directly or indirectly contributed for this study are duly acknowledged.

\section{Authors 'information}

Assaye Belay Gelaw: I was graduated BSc degree in Statistics from Wollega University in 2010. Ministry of higher education in Ethiopia has assigned me in Mizan-Tepi University as assistant instructor I and II. After two years' service of teaching, I have joined to Jimma University to study MSc in Biostatistics and graduated in 2015. Now, I am lecturer of Statistics at Mizan -Tepi University, College of Natural and Computational Science, Department of Statistics.

Solomon Abebaw Andargie: He was graduated BSc degree in Statistics from University of Gondar in 2010. Ministry of higher education in Ethiopia has assigned him in Mizan-Tepi University as assistant instructor I and II. After two years' service of teaching, he has joined to Jimma University to study MSc in Biostatistics and graduated in 2016. Now, he is lecturer of Statistics at Mizan -Tepi University, College of Natural and Computational Science, Department of Statistics.

\section{References}


[1] L. Van Der Hoek et al., "Identification of a new human coronavirus," Nat. Med., vol. 10, no. 4, pp. 368-373, 2004, doi: $10.1038 / \mathrm{nm} 1024$.

[2] CDC, "What you need to know about COVID-19 Coronavirus Disease," p. 314937, 2020.

[3] S. P. Adhikari et al., "A literature review of 2019 Novel Coronavirus during the early outbreak period: Epidemiology, causes, clinical manifestation and diagnosis, prevention and control," Infect. Dis. Poverty, vol. 9, no. 29, pp. 1-12, 2020.

[4] V. J. Munster, M. Koopmans, N. van Doremalen, D. van Riel, and E. de Wit, "A novel coronavirus emerging in China - Key questions for impact assessment," N. Engl. J. Med., vol. 382, no. 8, pp. 692-694, 2020, doi: 10.1056/NEJMp2000929.

[5] G. Pullano, F. Pinotti, E. Valdano, P. Y. Boëlle, C. Poletto, and V. Colizza, "Novel coronavirus (2019nCoV) early-stage importation risk to Europe, January 2020," Euro Surveill., vol. 25, no. 4, pp. 1-5, 2020, doi: 10.2807/1560-7917.ES.2020.25.4.2000057.

[6] W. (PRC) Aylward, Bruce (WHO); Liang, "Report of the WHO-China Joint Mission on Coronavirus Disease 2019 (COVID-19)," WHO-China Jt. Mission Coronavirus Dis. 2019, vol. 2019, no. February, pp. 16$24,2020$.

[7] D. L. Tadesse, "Ethiopia confirms first coronavirus case," in Live updates". Aljazeera.com. Archived from the original, 2020.

[8] ADB-factsheet, "The Economic Impact of the COVID-19 Outbreak on Developing Asia," vol. 9, no. 128, 2020, doi: 10.22617/BRF200096.

[9] O. Evans, "Socio-economic impacts of novel coronavirus: The policy solutions," B I Z E CONSQU ARTERLY, vol. 7, no. March, pp. 3-12, 2020.

[10] M. Demertzis, A. Sapir, S. Tagliapietra, and G. B. Wolf, "An effective economic response to the coronavirus in Europe," no. Policy Contribution 06/2020, Bruegel, 2020.

[11] U. Covid-, E. Response, and E. Sector, "UNESCO COVID-19 Education Response Education Sector issue notes Anticipated impact of COVID-19 on public expenditures on education and implication for UNESCO work," Educ. Sect., no. April, pp. 1-6, 2020.

[12] W. Mclennan, An Introduction to Sample Surveys: A User's Guide. Australi: AUSTRALIAN BUREAU OF STATISTICS, 1999.

[13] M. L. Mchugh, "Lessons in biostatistics The Chi-square test of independence," Lessons Biostat., vol. 23, no. 2, pp. 143-149, 2013. 
[14] C. J. Peng and G. M. Ingersoll, "An Introduction to Logistic Regression Analysis and Reporting," J. Educ. Res., vol. 96, no. 1, pp. 1-14, 2002, doi: 10.1080/00220670209598786.

[15] E. C. Norton, B. E. Dowd, and M. L. Maciejewski, "Odds Ratios - Current Best Practice and Use," JAMAGuide to Stat. Andm., vol. 320, no. 1, pp. 84-85, 2018, doi: 10.1001/jama.2017.3091.

[16] Z. Jasak, "BENFORD ' S LAW AND HOSMER-LEMESHOW TEST," J. Math. Sci. Adv. Appl. Vol., vol. 41, no. January 2016, pp. 57-73, 2016, doi: 10.18642/jmsaa.

[17] Y. Hou et al., "Adequacy of public health communications on H7N9 and MERS in Singapore: insights from a community based cross-sectional study," BMC Public Health, vol. 18, no. 436, pp. 1-11, 2018.

[18] S. Alsubaie, M. H. Temsah, A. A. Al-eyadhy, I. Gosadi, and M. Gamal, "Original Article Middle East Respiratory Syndrome Coronavirus epidemic impact on healthcare workers ' risk perceptions, work and personal lives," J. Infect. Dev. Ctries., vol. 13, no. 10, pp. 920-926, 2019, doi: 10.3855/jidc.11753.

[19] H. Giao, P. Le An, N. Thi Ngoc Han, T. Van Khanh, V. Kim Ngan, and V. Van Tam, "Knowledge and attitude toward COVID-19 among healthcare workers at District 2 Hospital, Ho Chi Minh City," Asian Pac. J. Trop. Med., vol. 13, no. March, pp. 6-11, 2020, doi: 10.4103/1995-7645.280396.

[20] K. S. Mya et al., "Awareness, perceived risk and protective behaviours of Myanmar adults on COVID-19," vol. 7, no. 5, pp. 1627-1636, 2020.

[21] A. BHAgaVATHULA, W. A. Aldhaleei, J. R. Rahmani, M. A. Mahabadi, and D. K. Bandari, "Novel Coronavirus (COVID-19) Knowledge and Perceptions: A Survey of Healthcare Workers (Preprint)," JMIR Public Heal. Surveill., vol. 6, pp. 1-9, 2020, doi: 10.2196/19160.

[22] K. O. Kwok et al., "Community responses during the early phase of the COVID-19 epidemic in Hong Kong: risk perception, information exposure and preventive measures," medRxiv, p. 2020.02.26.20028217, 2020, doi: 10.1101/2020.02.26.20028217.

[23] A. Sciences, "Knowledge, Attitude and Practice among Healthcare Professionals regarding COVID19: A cross-sectional survey from Pakistan," 2020.

[24] H. Z. Nooh et al., "Public awareness of coronavirus in Al-Jouf region, Saudi Arabia," J. Public Heal., vol. 13, no. 2020 Feb, pp. 1-8, 2020, doi: 10.1007/s10389-020-01209-y.

\section{Figures}




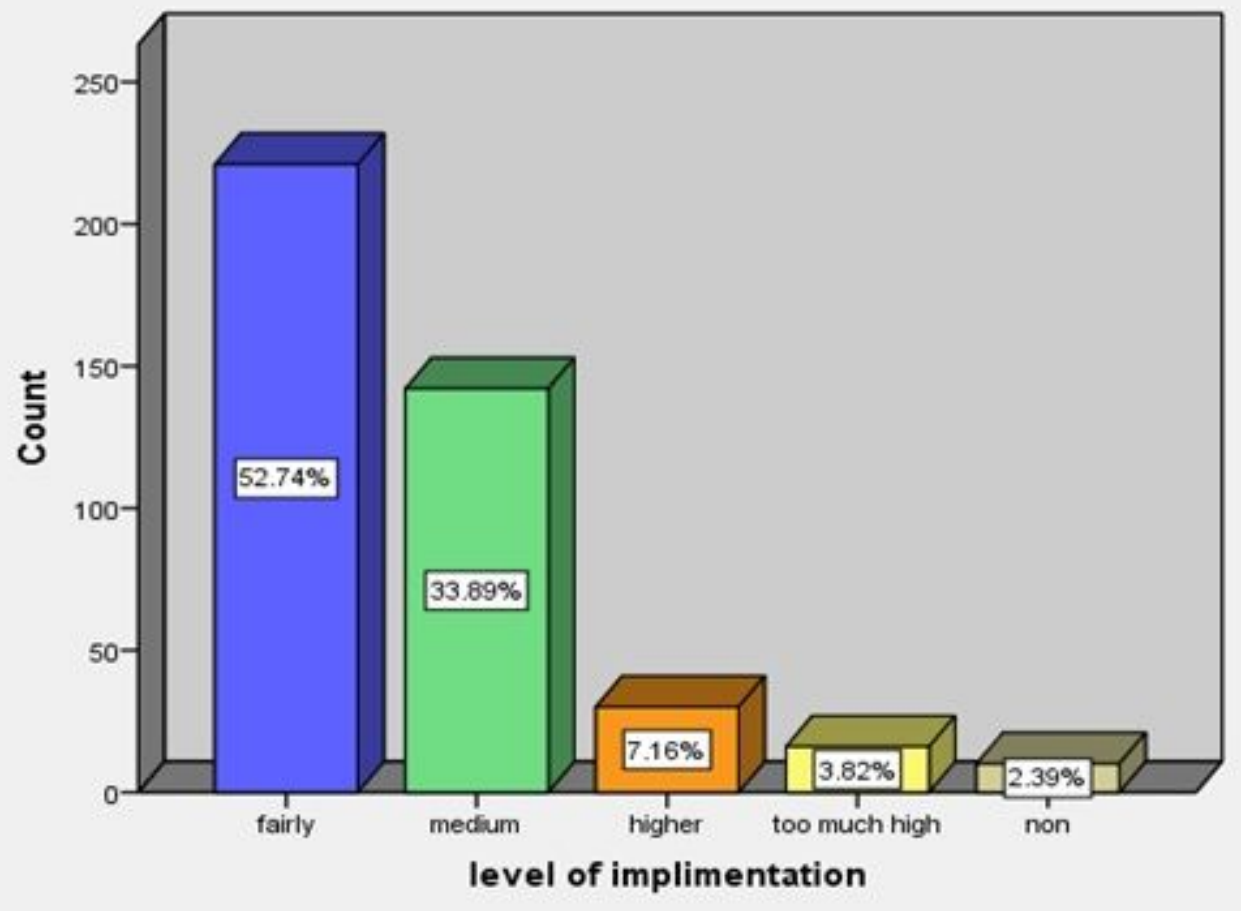

Figure 1

Level of implementation the government declaration regarding COVID-19 by individuals

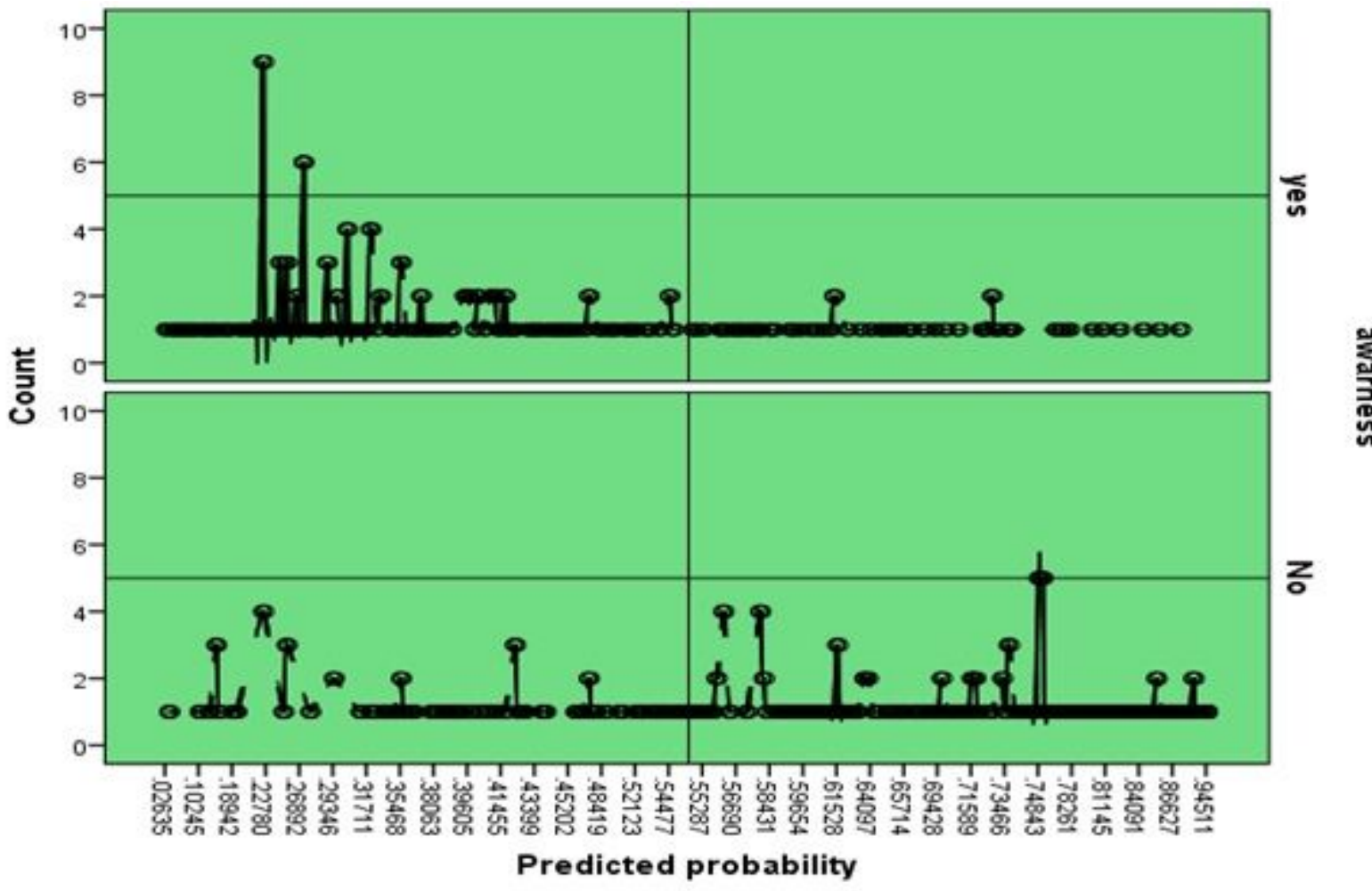

Figure 2 
Predicted probability of individual towards COVID-19

\section{Supplementary Files}

This is a list of supplementary files associated with this preprint. Click to download.

- Questionnare.docx 